\title{
An Improved Multistage Switched Inductor Boost Converter (Improved M-SIBC) for Renewable Energy Applications: A key to Enhance Conversion Ratio
}

\author{
Mahajan Sagar Bhaskar \\ Dept. of Electrical Engg., \\ Qatar University, Doha, Qatar. \\ sagar25.mahajan@gmail.com
}

\author{
Sanjeevikumar Padmanaban, Frede Blaabjerg \\ Dept. of Energy Technology, \\ Aalborg University, Denmark. \\ san@et.aau.dk, fbl@et.aau.dk
}

\section{Patrick William Wheeler \\ Dept. of Electrical \& Electronics Engg., \\ Nottingham University, UK. \\ pat.wheeler@nottingham.ac.uk}

\begin{abstract}
In this article, an improved Multistage Switched Inductor (M-SI) based power converter or Improved Multistage Switched Inductor Boost Converter (Improved M-SIBC) is proposed for renewable applications which provides a key to enhance voltage conversion ratio. In last decades, Switched Inductor (SI) and M-SI are the popular network/technique employed in DC-DC converter to achieve high voltage conversion ratio. An improved SI and M-SI network/technique is proposed to enhance the existing the voltage conversion capabilities of SI and M-SI by replacing central uncontrolled switches by polarized capacitor. The anticipated power converter configuration combines the feature of conventional boost converter and improved M-SI. The voltage conversion a capability is depends on the number of stages of M-SI and ON time of control switch. The operation modes and characteristics of proposed converter with steady state mathematical analysis for $\mathrm{N}$-stages are discussed in detail. Moreover, the proposed converter compared with existing converter in terms of voltage conversion ratio and the detail of number of components is also provided. Matrix Laboratory R2016a simulation results of $100 \mathrm{~W}$ proposed improved M-SIBC with considering three stages are provided and the results always shows a good agreement with theoretical analysis and also validates the improved M-SI network concept.
\end{abstract}

Keywords-Multistage; Switched Inductor; DC-DC; Renewable Energy; Voltage Conversion Ratio, Matrix Laboratory R2016a.

\section{INTRODUCTION}

Nowadays, renewable energy sources especially wind and photovoltaic technologies are well accepted due to over utilization and depletion of fossil fuels which increases the hotness of earth and also creates several environment issues. In photovoltaic, wind and fuel cells applications, power converters are stipulated and play a vital role for conditioning and conversion of energy [1]-[2]. Furthermore, DC-DC power converter used in renewable energy applications must have efficiency and high voltage capabilities with reduce cost and components. Practically, conventional DC-DC boost converters are not suitable for high voltage conversion due to the effect of inductor internal resistance, voltage stress across controlled switch (MOSFET) and uncontrolled switch (diodes). In addition, very large $T_{o n} / T$ ( $T_{o n}$ is $\mathrm{ON}$ time of switch, $T=1 / f, f$ is switching frequency) of MOSFET result in a severe reverse recovery issue of diodes. Recently, numerous DC-DC power converter configurations are addressed to achieve high voltage conversion ratio without using large $T_{\text {on }} /$ ffor MOSFET [1]-[7]. Using transformer, a fly-back converter is designed with high voltage conversion and
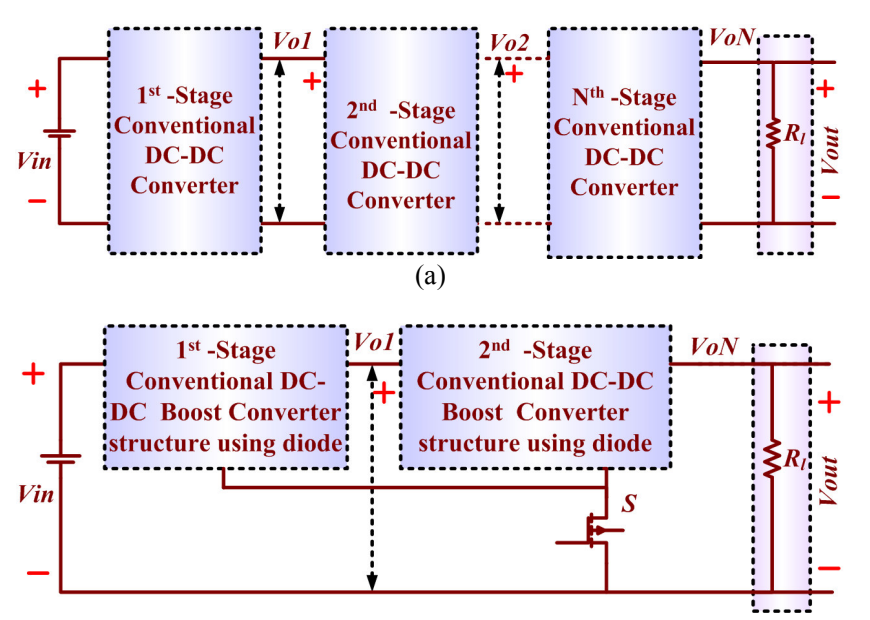

(b)

Fig.1 Generalized structure of DC-DC power converter (a) Cascaded power converter (b) Quadratic power converter

electrical isolation capability but, not suitable for many applications due to transformer leakage inductance and high voltage stress of MOSFET. In, [3], DC-DC converters are addressed with regeneration energy techniques to reduce the voltage stress and recycle the leakage inductance energy. DCDC converter designed by employing coupled inductor and transformer with or without electric isolation is another solution to attain high voltage conversion ratio, high efficiency, and low voltage stress across switch [4]-[5]. These types of power converters are large in size due to transformer and having more cost and weight.

Recently numerous boosting techniques without transformer are proposed to overcome the drawback of transformer in DC-DC converter [6]-[7]. The multiple boosting techniques are employed in a single power converter also called multistage power converter to enhance the voltage conversion ratio capability with reduce $T_{o n} / T$. Multistage DCDC power converter includes cascaded converter, quadratic converter, switched capacitor based converter, switched inductor based converter, voltage lift converter, voltage multiplier based converter, and XY converter family [8]-[20]. The block diagram of cascaded and quadratic power converter is depicted in Fig. 1(a) and Fig. 1(b) respectively. In cascaded power converter, several conventional boost converters are connected in cascaded manner, where output of $(N-1)^{t h}$ stage is feed as input to the $N^{\text {th }}$ stage [8]. Large number of inductors, capacitors, and control switches with various current and 


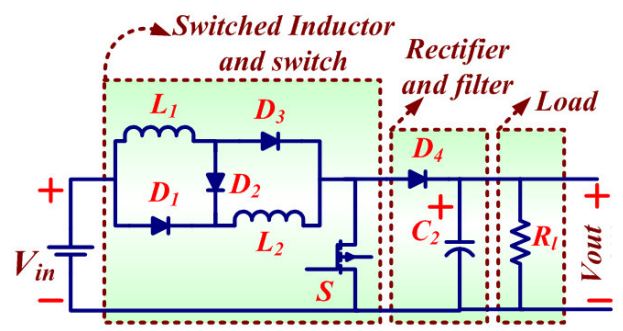

(a)

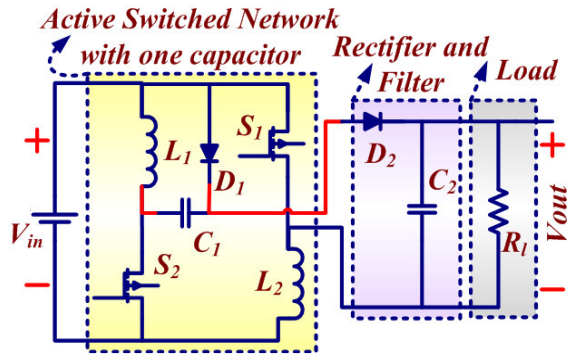

(d)

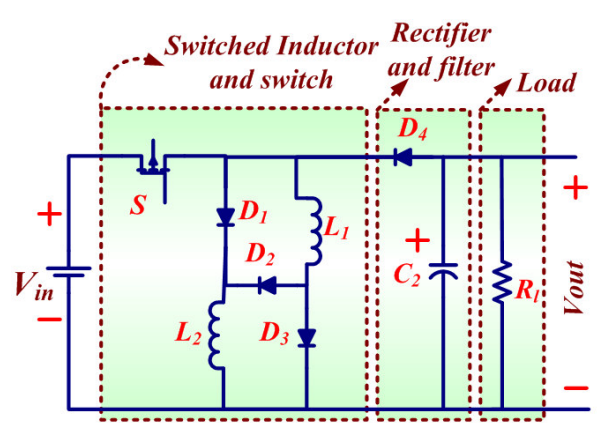

(b)

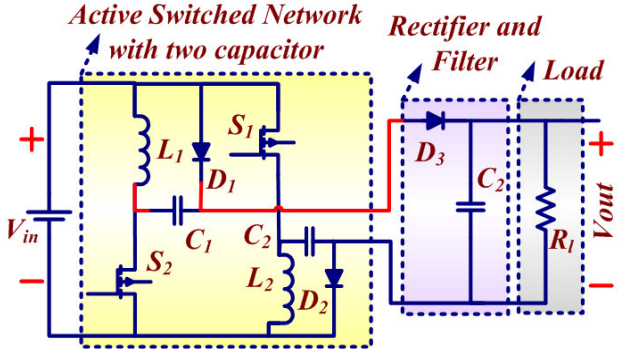

(e)

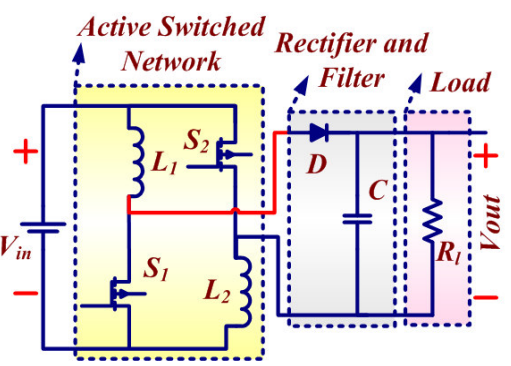

(c)

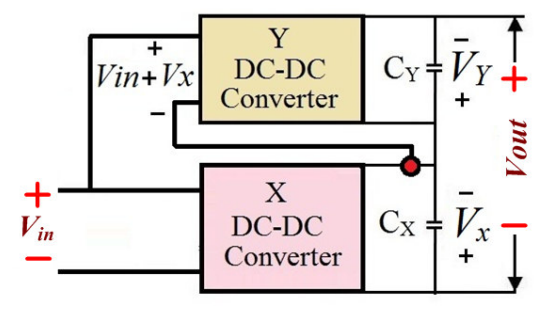

(f)

Fig. 2 Recently proposed Switched Inductor based DC-DC power converter (a) Switched Inductor Boost Converter (SI-BC) (b) Switched Inductor Buck Boost Converter (SI-BBC) (c) Converter-I (d) Converter-II (e) Converter-III (f) Generalized structure of XY converter family.

voltage rating, high voltage stress across switch, and complex control circuitry are the main drawback of cascaded converter. Quadratic converter is proposed by cascading two boost converters in special manner using single switch to overcome the drawback of large number of control switches in cascaded converter [9]. The high voltage stress across switch (equal to output voltage) and large rating of inductor and capacitor are the main drawback of quadratic converter. Because of numerous attractive features like high efficiency, low weight, magnetic-less structure, switched capacitor structures gaining more popularity in DC-DC power converters [10]-[11]. These DC-DC converters provides a high efficiency with good regulation of output voltage and therefore several DC-DC switched capacitor based power converters are proposed in literature. Pulsating input current, unidirectional power flow, large number of capacitor with various rating and large number of switching devices are the main drawback of switched capacitor based DC-DC converter. To maintain high efficiency the main hurdle for practical design is TDPR (Total Device Power Rating) of converter. Due to these reasons, the switched capacitor converters have limited voltage conversion ratio and mostly employed for low power applications

Hybridization of voltage multiplier with conventional boost converters is another popular solution to achieve high voltage conversion ratio with low voltage across switch. In [4], voltage multiplier circuitry is employed with conventional (Boost, Buck-Boost) and derived (Cuk, SEPIC) DC-DC converter. In [12], Nx multilevel power converter is proposed with inverting output voltage capability which provides $\mathrm{N}$ times voltage conversion ratio compared to conventional boost converter. In [13], Nx interleaved multilevel power converter is proposed with reduce current and voltage ripples which also provides high voltage conversion ratio. To enhance the voltage conversion ratio, $2 \mathrm{Nx}$ and $4 \mathrm{Nx}$ interleaved multilevel power converter are proposed which provides $2 \mathrm{~N}$ and $4 \mathrm{~N}$ times voltage conversion ratio compared to conventional boost converter [14]-[16]. In [15], inverting $\mathrm{Nx}$ and $2 \mathrm{Nx}$ multilevel power converter is addressed to achieve inverting voltage with high voltage conversion ratio. These voltage multiplier based power converter provides a high voltage conversion ratio but the main drawbacks are capacitor voltage balancing, difficult in selection of capacitor with proper time constant $(R C)$, large number of capacitor and diodes, the energies is flowing through many multiple stages which reduces the efficiency and the energy conversion is completely depends on charging and discharging of capacitors.

Switched Inductor (SI) based DC-DC converters also provide a viable solution to achieve high voltage conversion ratio [16]-[17]. In SI, two inductors are charged in parallel and discharge in series. Fig. 2(a) and 2(b) depicts the power circuit of Switched Inductor Boost Converter (SI-BC) and Switched Inductor Buck Boost Converter (SI-BBC) respectively. The power circuit SI-BC is designed by replacing inductor of conventional boost converter with SI. The main benefit of SI-BC is voltage conversion ratio is augmented by $(1+D)$ times compared to conventional boost converter. The power circuit SI-BBC is designed by replacing inductor of conventional buck-boost converter with SI. The main benefit of SI-BBC is voltage conversion ratio is augmented by two times compared to conventional buck-boost converter. The power circuitry of SI-BC and SI-BBC converter is simple and single switch is required. Large voltage stress across switch is the main drawback of the SI-BC and SI-BBC configurations. In [17], three new power converters (Converter I, II and III) are addressed to overcome the drawback of SI-BC. All the three converters have low voltage stress across switch, high voltage conversion ratio and the minimum numbers of power devices are present in the path of current flow. The power 


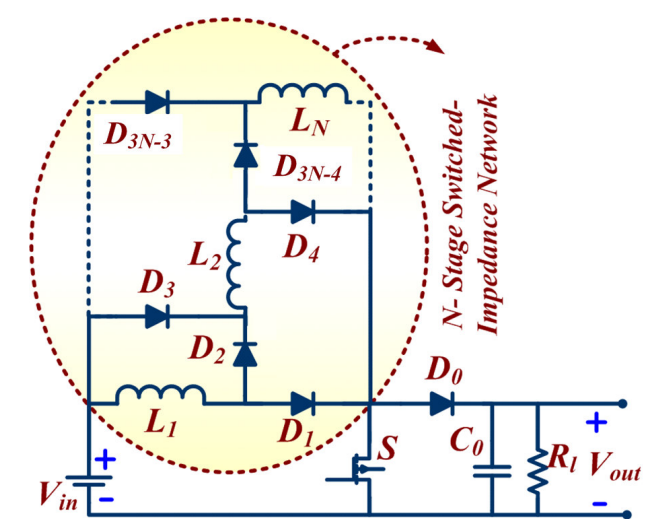

Fig. 3 Power circuit of existing N-stages Switched Inductor Boost Converter (M-SIBC for N stages)

circuit of converter I, II and III is depicted in Fig. 2(c), Fig. 2(d) and Fig. 2(e) respectively. Converter-I is designed with the help of Active Switched Inductor (A-SI) network and filter. Additionally, Converter-II required one capacitor-diode circuitry and Converter-III required two capacitor-diode circuitries. These converters are not suitable for high voltage with high power application and also required two control switch and additional capacitors-diodes circuitry.

$\mathrm{XY}$ converter family is another solution to achieve high voltage conversion ratio and to overcome the drawback of voltage multiplier based power converter [18]-[19]. XY converter family consists of sixteen configurations which are designed with the help of Switched Inductor (SI), Voltage Lift Switched Inductor (VLSI) and modified Voltage Lift Switched Inductor (mVLSI). In XY converter, two derived buck-boost converters called $\mathrm{X}$ and $\mathrm{Y}$ converters are connected in special arrangement. The generalized structure of $\mathrm{XY}$ converter family is shown in Fig. 2(f). Discontinuous input current is the main drawback of XY converter family, thus less utilization of input source. In [20], Multistage Switched Inductor Boost Converter (M-SIBC) is proposed for renewable energy application. The M-SIBC power circuit is depicted in Fig.3. To design N-Stage M-SIBC, N number of inductor, $3 \mathrm{~N}-2$ uncontrolled switches, single capacitor and single switch is required. In this work, a key solution is provided to enhance the voltage conversion ratio of M-SIBC for renewable applications. An improved M-SI network or technique is proposed by replacing central uncontrolled switches of $\mathrm{N}$ stage SI network by polarized capacitor. The mode of operation with mathematical analysis is explained in the following section. Matrix Laboratory R2016a simulation results are provided to validates the performance and functionality of Improved M-SIBC.

\section{IMPROVED M-SIBC: POWER CIRCUITRY AND WORKING MODES}

An improved M-SI network is proposed to enhance the voltage conversion ratio of boost converter. The power circuit of conventional boost converter Improved Two-stage SIBC is shown in Fig. 4(a). Its noticed that the circuitry of conventional boost converter and improved single-stage SIBC is same and having same performance. Two diodes, two inductor and single capacitor are required to design improved two-stage SI network. In two-stage SIBC, input supply is directly connected to improved two-stage SI network and remaining circuitry is similar to conventional boost converter. In improved two-stage SIBC, two inductor $\left(L_{1}\right.$ and $\left.L_{2}\right)$ and single capacitor $\left(C_{l}\right)$ are charged in parallel when control switch $\mathrm{S}$ is turned $\mathrm{ON}$ and discharge in series with input voltage $V_{\text {in }}$ when control switch $S$ is turned OFF. Diode $D_{l}$ and $D_{2}$ are forward biased and diode $D_{0}$ is reversed biased when switch $S$ is turned ON. Diode $D_{1}$ and $D_{2}$ are reversed biased and diode $D_{0}$ is forward biased when switch $S$ is turned OFF. The power circuit of improved three-stage SI network based boost converter (Improved three-stage SIBC) is shown in Fig. 4(b). Four diodes, three inductors and two capacitors are required to design improved three-stage SI network. In threestage SIBC, input supply is directly connected to improved three-stage SI network and remaining circuitry is similar to conventional boost converter. In improved three-stage SIBC, three inductor $\left(L_{1}, L_{2}\right.$ and $\left.L_{3}\right)$ and two capacitors $\left(C_{1}\right.$ and $\left.C_{2}\right)$ are charged in parallel when control switch $S$ is turned $\mathrm{ON}$ and discharge in series with input voltage $V_{\text {in }}$ when control switch $S$ is turned OFF. Diode $D_{1}, D_{2}, D_{3}$ and $D_{4}$ are forward biased and diode $D_{0}$ is reversed biased when switch $S$ is turned ON. Diode $D_{1}, D_{2}, D_{3}$ and $D_{4}$ are reversed biased and diode $D_{0}$ is forward biased when switch $S$ is turned OFF.
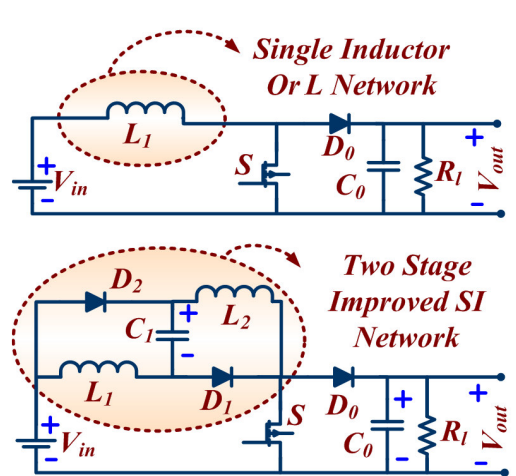

(a)

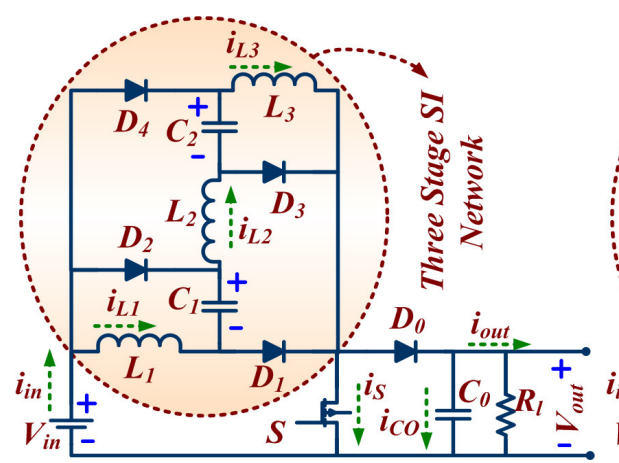

(b)

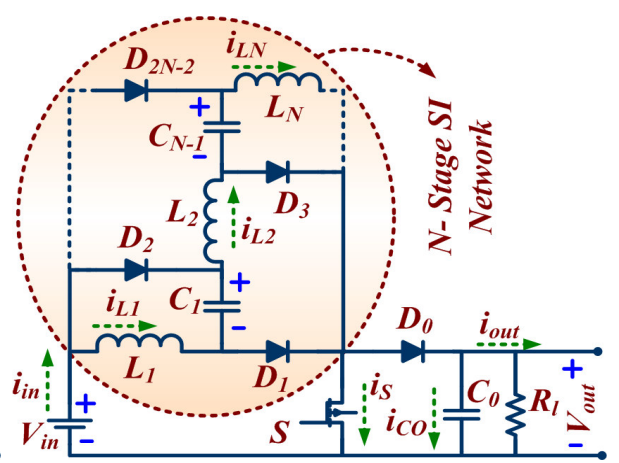

(c)

Fig. 4 Power circuit of proposed Improved M-SIBC and its stages (a) Conventional boost converter (b) Improved Two-stage SIBC (c) Improved Three-stage SIBC (d) Improved N-stage SIBC. 


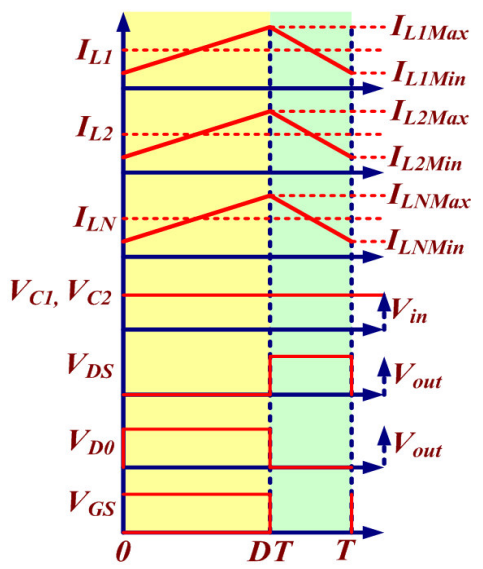

Fig. 5 Characteristics waveform of Improved N-stage SIBC

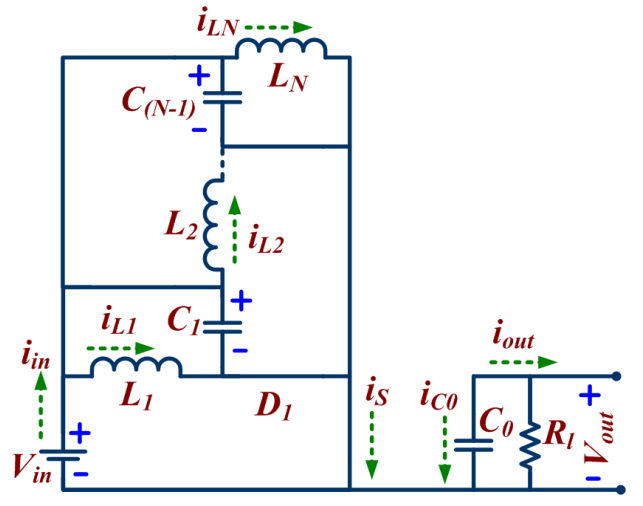

(a)

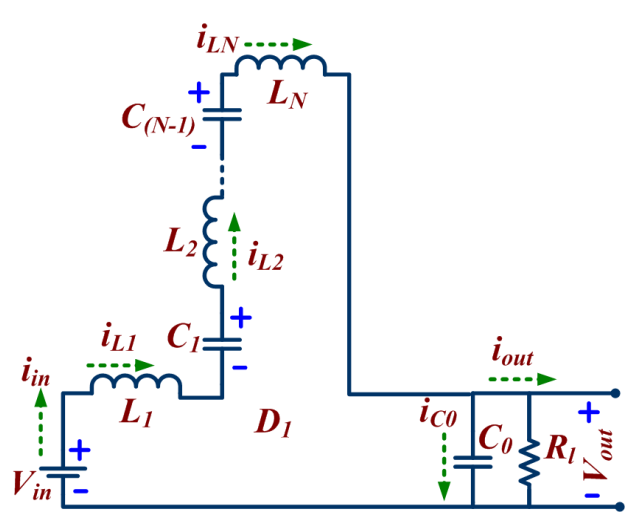

(b)

Fig. 6 Equivalent circuit of Improved N-stage SIBC (a) when switch is ON (b) when switch is OFF

The power circuit of improved N-stage SI network based boost converter (Improved N-stage SIBC) is shown in Fig. 4(c). 2(N-1) diodes, $N$ inductors and $N-1$ capacitors are required to design improved $\mathrm{N}$-stage SI network. In $\mathrm{N}$-stage SIBC, input supply $V_{\text {in }}$ is directly connected to improved three-stage SI network and the remaining circuitry is similar to conventional boost converter. In improved $\mathrm{N}$-stage SIBC, $\mathrm{N}$ inductors $\left(L_{1}, L_{2}, L_{3} \ldots \ldots\right.$ and $\left.L_{N}\right)$ and $N-1$ capacitors $\left(C_{1}\right.$ and $C_{2} \ldots \ldots$ and $\left.C_{N-1}\right)$ are charged in parallel when control switch $S$ is turned $\mathrm{ON}$ and discharge in series with input voltage $V_{\text {in }}$ when control switch $S$ is turn OFF. Diode $D_{1}, D_{2}, D_{3} \ldots \ldots$...and $D_{2(\mathrm{~N}-\mathrm{l})}$ are forward biased and diode $D_{0}$ is reversed biased when switch $S$ is turned ON. Diode $D_{1}, D_{2}, D_{3} \ldots \ldots$ and $D_{2(N-1)}$ are in reversed biased and diode $D_{0}$ is forward biased when switch Sis turned OFF. Fig. 5 depicts the characteristics waveform of Improved N-stage SIBC. ON state and OFF state equivalent circuitry of N-stage SIBC is shown in Fig. 6(a) and Fig. 6(b). Table-I provides the information regarding requirement of components and semiconductor devices to design proposed Improved M-SIBC. For better understanding, the graphical 3dimensional view of the relation between number of stages $(N)$, capacitors $\left(N_{C}\right)$ and diodes $\left(N_{D}\right)$ is shown in Fig. 7. In the next section voltage gain analysis of proposed Improved $M-$ SIBC converter is discussed in detail.

\section{STEADY STATE ANALYSIS OF IMPROVED M-SIBC AND COMPARISON WITH EXISTING POWER CONVERTERS}

Following assumption is considered to analyze the steady state characteristic of proposed improved M-SIBC.1) All the devices having zero ON-state resistance, 2) Internal resistance of inductor is zero, 3) Always maintain a constant voltage across capacitor and 4) All the capacitors are sufficiently charging and discharging.

When switch $S$ is ON,

TABLE I. NUMBER OF DEVICES/ COMPONENTS FOR IMPROVED M-SIBC

\begin{tabular}{c|c|c|c|c}
\hline \multicolumn{5}{|c}{ Number of } \\
\hline Stages & Inductors & Capacitors & Switches & Diodes \\
\hline 1 & 1 & 1 & 1 & 1 \\
\hline 2 & 2 & 2 & 1 & 3 \\
\hline 3 & 3 & 3 & 1 & 5 \\
\hline $\mathrm{N}$ & $\mathrm{N}$ & $\mathrm{N}$ & 1 & $2 \mathrm{~N}-1$ \\
\hline
\end{tabular}

$$
\left.\begin{array}{l}
V_{L}=V_{L 1}=V_{L 2} \ldots \ldots=V_{L N}=V_{\text {in }} \\
V_{C 1}=V_{C 2}=\ldots \ldots \ldots . . V_{C N-1}=V_{\text {in }} \\
V_{C 0}=V_{\text {out }}, V_{D S}=0
\end{array}\right\}
$$

When switch $S$ is OFF,

$$
\left.\begin{array}{l}
V_{\text {in }}-V_{L 1}+V_{C 1}-V_{L 2}+V_{C 2} \cdots .-V_{L N}=V_{\text {out }} \\
V_{L}=V_{L 1}=V_{L 2} \cdots=V_{L N}, V_{C 1}=V_{C 2} \cdots=V_{C N-1}=V_{\text {in }} \\
V_{\text {in }}+(N-1) V_{\text {in }}-N V_{L}=V_{\text {out }} \\
V_{L}=V_{\text {in }}-\left(V_{\text {out }} / N\right), V_{C 0}=V_{\text {out }}, V_{D S}=V_{\text {out }}
\end{array}\right\}
$$

Using volt second balance method on inductor and following conversion ratio can be obtained where $N$ is number

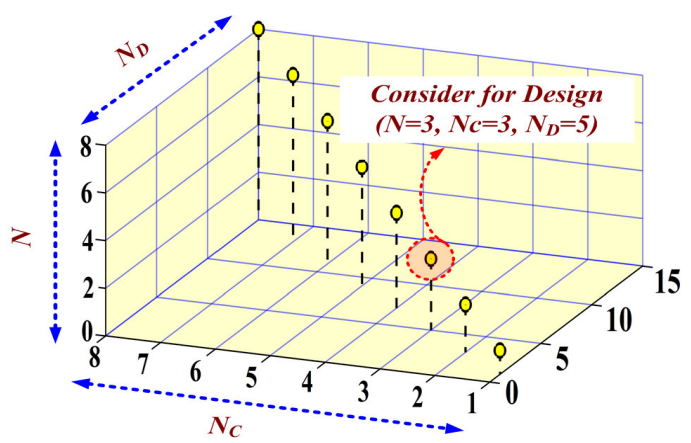

Fig. 7 Graphical view of the relation between number of stages $(N)$, capacitors $\left(N_{C}\right)$ and diodes $\left(N_{D}\right)$

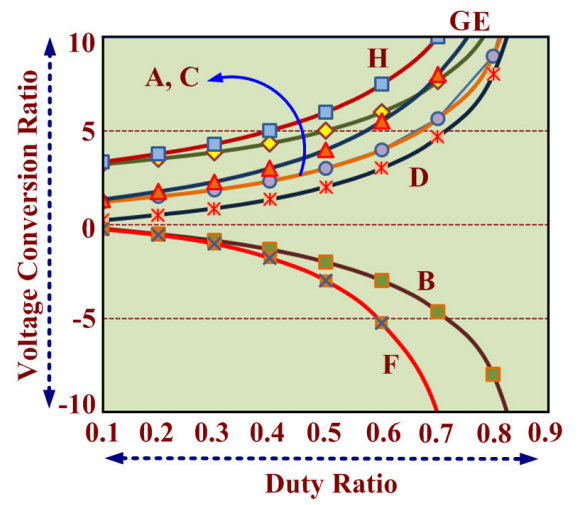

Fig. 8 Comparison of improved M-SIBC with existing converter (A: SIBC, B: SI-BBC, C: Converter-I, D: Converter-II, E: Converter-III, F: LL Converter, G: existing M-SIBC, H: Improved M-SIBC) 
of stages and $D$ is duty cycle,

$$
V_{\text {out }} / V_{\text {in }}=N /(1-D) \text { and } I_{\text {out }} / I_{\text {in }}=(1-D) / N
$$

Thus, Improved M-SIBC provides $\mathrm{N}$ times higher voltage conversion ratio compared to conventional boost converter. In Fig. 8, Improved M-SIBC compared with recently proposed SI based DC-DC converter in terms of voltage conversion ratio and it is observed that proposed converter attain higher voltage conversion ratio at low duty cycle. 3-dimensional view of relations between voltage conversion ratio, duty cycle and number of stages is shown in Fig. 9(a). 3-dimensional view of relations between current conversion ratio, duty cycle and number of stages is shown in Fig. 9(b). For the better understanding, the left and right view of Fig. 9(a) is shown in Fig. 9(c) and 9(d) respectively. From the plot it is observed that voltage conversion ratio is increased with number of stages and duty cycle. Right and left view of Fig. 9(b) is shown in Fig. 9(e) and 9(f) respectively. From the plot it is
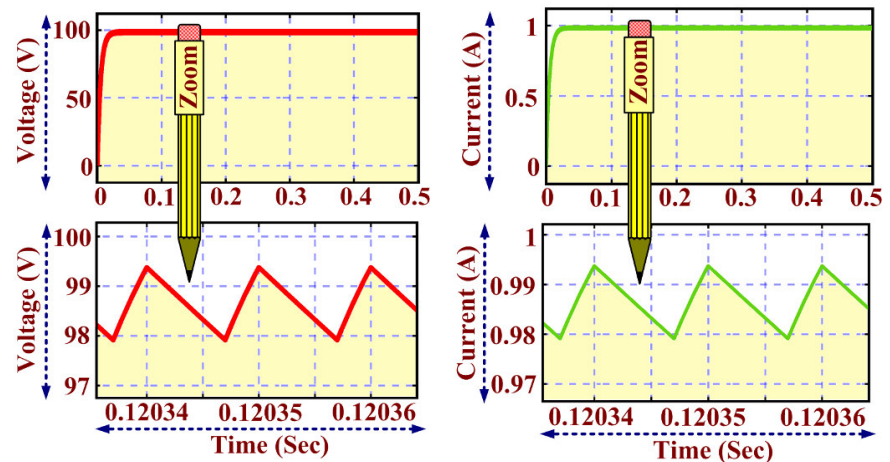

(a)

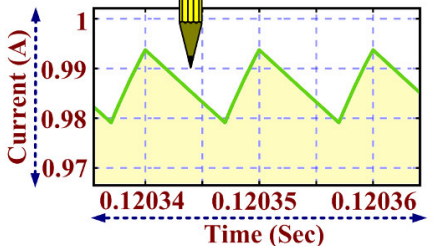

(b)

observed that current conversion ratio is decreased with the number of stages and duty cycle.

\section{Numerical Simulation Results AND Discussion}

Matrix Laboratory R2016a Simulink is used to verify the performance and functionality of improved M-SIBC. Improved M-SIBC is simulated for three-stage with $10 \mathrm{~V}$ input supply, $100 \mathrm{~W}$ power, $70 \% T_{o n} / T$ and $100 \mathrm{kHz}$ switching frequency. High switching frequency is used to reduce rating of inductor and semiconductor devices. $L_{1}, L_{2}$ and $L_{3}=$ $100 \mu \mathrm{H}, C_{0}=5 \mu \mathrm{F}, C_{1}$ and $C_{2}=220 \mu \mathrm{F}$ are used to design threestage proposed improved M-SIBC. Obtained output voltage waveform and its ripple content are shown in Fig. 10(a). It is investigated that nearly $100 \mathrm{~V}$ with $1 \mathrm{~V}$ ripple is achieved. Hence, voltage conversion ratio at $70 \%$ duty cycle is nearly 10. Obtained output current waveform and its ripple content are shown in Fig. 10(b). It is investigated that nearly $1 \mathrm{~A}$ with $0.01 \mathrm{~A}$ ripple is achieved. Obtained drain to source voltage of

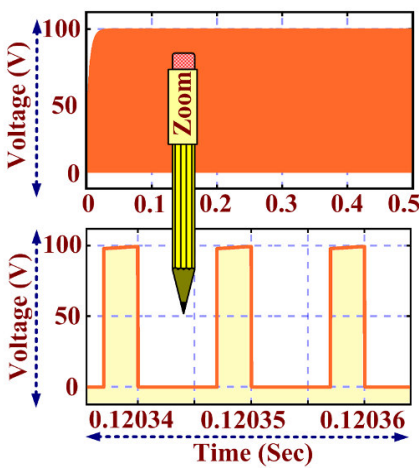

(c)

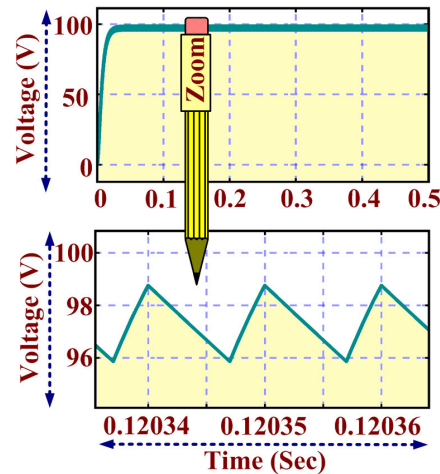

(d)

(c) Output Current (d) Drain to Source voltage of control switch

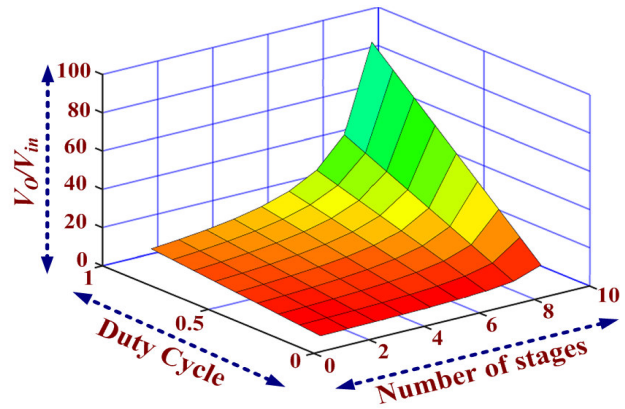

(a)

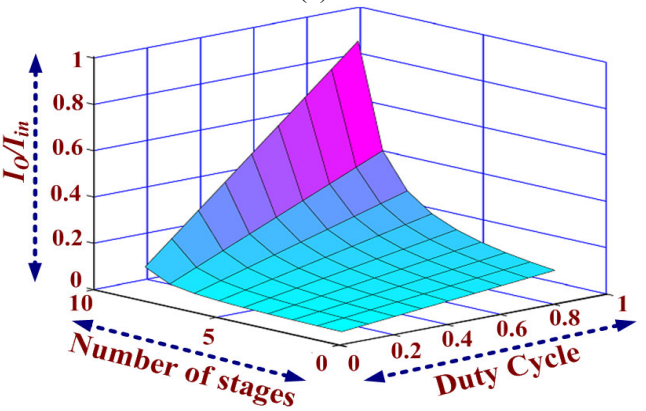

(b)

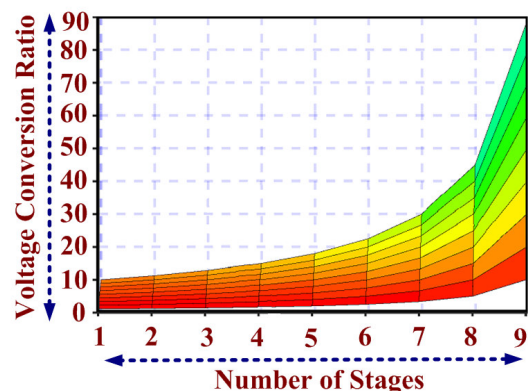

(c)

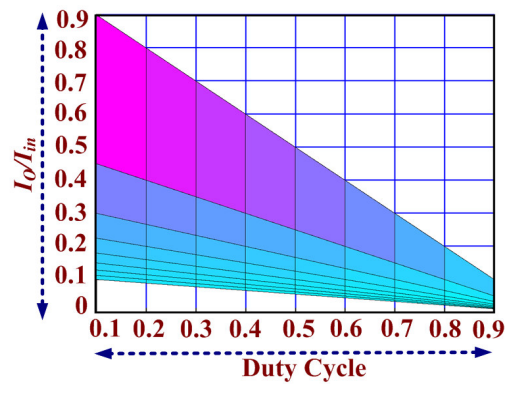

(e)

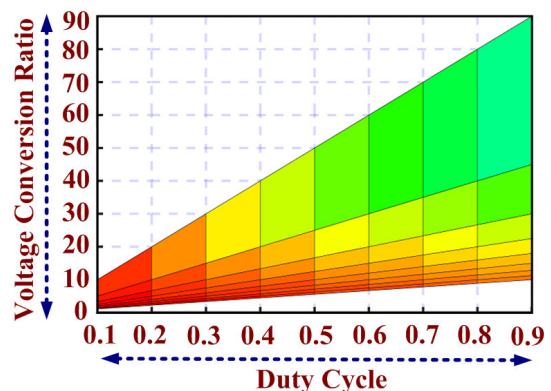

(d)

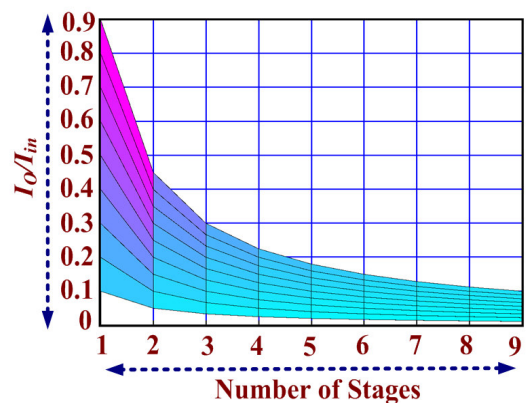

(f)

Fig. 9 Plot of Improved M-SIBC (a) Relation between number of stages $(N)$, voltage conversion ratio and duty cycle (b) Relation between number of stages $(N)$, current conversion ratio and duty cycle (c) Left view of Fig. 9(a), (d) Right view of Fig. 9(a), (e) Right view of Fig. 9(b), (f) Left view of Fig. 9(b). 
switch $\mathrm{S}$ is shown in Fig. 10(c). It is investigated that the voltage across switch in OFF state is $100 \mathrm{~V}$ and it is equal to output voltage. The obtained power waveform with ripples is shown in Fig. 10(d) and $98 \mathrm{~W}$ power is observed (2W is drop due to small on-state resistance of diode and switch).

\section{CONCLUSIONS}

An Improved Multistage Switched Inductor Boost Converter (Improved M-SIBC) is proposed for Renewable energy applications. A key is provided to improve the voltage conversion ratio of existing M-SIBC. The striking feature of Improved M-SIBC are 1) Required single switch and single gate driver, 2) High voltage conversion ratio without using high $\left.T_{o n} / T, 3\right)$ Configuration is derived from conventional boost converter and 4) Easy to increase number of stages without disturbing the output end of the converter. The converter operation modes are simple and converter circuitry is easy in control due to only single switch. Simulation results are provided which validates the proposed concept and converter functionality. The experimental setup is under investigation at Aalborg University, Denmark.

\section{REFERENCES}

[1] M. Forouzesh, Y. Siwakoti, S. Gorji, F. Blaabjerg, B. Lehman, "Step-Up DC-DC Converters: A Comprehensive Review of Voltage-Boosting Techniques, Topologies, and Applications," IEEE Trans. on Power Electronics, vol. 32, no. 12, pp. 9143-9178, Dec. 2017.

[2] F. Blaabjerg, Y. Yang, K. Mam, X. Wang, "Power Electronics-The key Technology for renewable energy system Integration," Conf. Proc, IEEE $4^{\text {th }}$ Intl. conf. on renewable Energy Research and Application, IEEEICRERA'15, Palermo (Italy), 22-25 Nov. 2015.

[3] C. M. Wang, "A novel ZCS-PWM flyback converter with a simple ZCSPWM commutation cell," IEEE Trans. Ind. Electron., vol. 55, no. 2, pp. 749-757, Feb. 2008.

[4] A. Chub, D. Vinnikov, F. Blaabjerg, F. Z. Peng, "A Review of Galvanically Isolated Impedance-Source DC-DC Converters," IEEE Trans. on Power Electronics, vol. 31, no. 4, pp. 2808-2828, Apr. 2016.

[5] P. He, A. Khaligh, "Comprehensive Analyses and Comparison of $1 \mathrm{~kW}$ Isolated DC-DC Converters for Bidirectional EV Charging Systems," IEEE Trans. on Transp. Elect., vol. 3, no. 1, pp. 147-156, Mar. 2017.

[6] L. Wuhua, H. Xiangning "Review of nonisolated high-step-up $\mathrm{dc} / \mathrm{dc}$ converters in photovoltaic grid-connected applications" IEEE Trans. Ind. Electron., vol.58, p.p1239-1250, 2011.

[7] F. L. Tofoli, W. Josias de Paula, D. de S. Oliveira Júnior, D. de C. Pereira, "Survey on non-isolated high-voltage step-up dc-dc topologies based on the boost converter," IET Power Electron., vol. 8, no. 10, pp. 2044-2057, Oct. 2015.

[8] S. H. Chincholkar, W. Jiang, C. Y. Chan, "An Improved PWM-based Sliding-Mode Controller for a Dc-Dc Cascade Boost Converter," IEEE Transactions on Circuits and Systems II, no. 99, pp. 1-1, 2017.

[9] O. Lopez-Santos, L. Martinez-Salamero, G. Garcia, H. ValderramaBlavi, D. A. Zambrano-Prada, "Steady-State Analysis of Inductor Conduction Modes in the Quadratic Boost Converter," IEEE Trans. on Power Electronics, vol. 32, no. 3, pp. 2253-2264, Mar. 2017.

[10] S. B. Mahajan, P.Sanjeevikumar, F. Blaabjerg, "Multistage DC-DC Step-Up Self Balanced and Magnetic Component Free Converter for Photovoltaic Applications -Hardware Implementation", Energies Journal, MDPI AG Publications, Switzerland, vol. 10, no. 5, Issue 719, pp. 1-28, 18 May 2017.

[11] W. Qian, D. Cao, J. G. Cintron-Rivera, M. Gebben, D. Wey, F. Z. Peng, "A Switched-Capacitor DC-DC Converter With High Voltage Gain and Reduced Component Rating and Count," IEEE Trans. on Ind. Applications, vol. 48, no. 4, pp. 1397-1406, Jul. 2012.
[12] S. B. Mahajan, P. Sanjeevikumar, O. Ojo, M. Rivera, R. Kulkarani: "Non-Isolated and Inverting Nx Multilevel Boost Converter For Photovoltaic DC Link Applications"Conf. Proc., IEEE Intl. Conf. on Automatica IEEE-ICA-ACCA'16, pp. 1-8, Curico (Chile), 19-21 Oct. 2016.

[13] M. S. Bhaskar, R. M. Kulkarni, S. Padmanaban, P. Siano, F. Blaabjerg, "Hybrid non-isolated and non inverting $\mathrm{Nx}$ interleaved DC-DC multilevel boost converter for renewable energy applications," Conf. Proc., IEEE 16 ${ }^{\text {th }}$ Intl. Conf. on Environment and Electrical Engineering, IEEE-EEEIC'16, pp. 1-6, Florence (Italy), 7-10 June 2016.

[14] M. S. Bhaskar, P. Sanjeevikumar, F. Blaabjerg, V. Fedak, M. Cernat, R. M. Kulkarni, "Non isolated and non-inverting Cockcroft-Walton multiplier based hybrid $2 \mathrm{Nx}$ interleaved boost converter for renewable energy applications," Conf. Proc., IEEE Intl. Power Electronics and Motion Control Conference, IEEE-PEMC'16, pp. 146-151, Verna (Bulgaria), 25-26 Sept. 2016.

[15] M. S. Bhaskar, P. Sanjeevikumar, F. Blaabjerg, O. Ojo, S. Seshagiri, and R. Kulkarni, "Inverting $\mathrm{Nx}$ and $2 \mathrm{Nx}$ non-isolated multilevel boost converter for renewable energy applications", Conf. Proc., IET Intl. Conf. on Clean Energy and Technology,IET-CEAT'16, Kuala Lumpur (Malaysia), pp. 1(8.)-1(8.), 14-15 Nov. 2016.

[16] M. S. Bhaskar, S. Padmanaban, F. Blaabjerg, L. E. Norum, and A. H. Ertas, " $4 \mathrm{Nx}$ Non-Isolated and Non-Inverting hybrid Interleaved Multilevel Boost Converter based on VLSIm Cell and Cockcroft Walton voltage multiplier for renewable energy applications," Conf. Proc., IEEE Intl. Conf. on Power Electronics, Drives and Energy Systems, IEEEPEDES'16, Trivandrum (India), pp. 1-6, 14-17 Dec. 2016

[17] L. S. Yang, T. J. Liang, J. F. Chen, "Transformerless DC-DC Converters With High Step-Up Voltage Gain," IEEE Trans. on Ind. Electronics, vol. 56, no. 8, pp. 3144-3152, Aug. 2009.

[18] S. B. Mahajan, P. Sanjeevikumar, P. Wheeler, F. Blaabjerg, M. Rivera, R. Kulkarni, "X-Y converter family: A new breed of buck boost converter for high step-up renewable energy applications," Conf. Proc., IEEE Intl. Conf. on Automatica IEEE-ICA-ACCA'16, pp. 1-8, Curico (Chile), 19-21 Oct. 2016.

[19] M. S. Bhaskar, P. Sanjeevikumar, F. Blaabjerg, R. Kulkarni, S. Seshagiri, A. Hajizadeh "Novel LY Converter Topologies for High Gain Transfer Ratio- A New Breed of XY Family" Conf. Proc., IET $4^{\text {th }}$ IET Intl. Conf. On Clean Energy and Technology, IET-CEAT'16, pp. 1-8, Kuala Lumpur (Malaysia), 14-15 Nov. 2016.

[20] P. K. Maroti, P. Sanjeevikumar, M. S. Bhaskar, F. Blaabjerg, V. K. Ramachandaramurthy, P. Siano, V. Fedak "Multistage Switched Inductor Boost Converter for Renewable Energy Applications" Conf. Proc., IEEEConference on Energy Conversion, IEEE-CENCON'17, pp. 311-316, Kuala Lumpur (Malaysia), 30-31Oct. 2017. 